\title{
Meditation and the Startle Response: A Case Study
}

\author{
Robert W. Levenson \\ University of California, Berkeley
}

\author{
Paul Ekman \\ University of California, San Francisco
}

\author{
Matthieu Ricard \\ Shechen Tennyi Dargyeling Monastery, Kathmandu, Nepal
}

\begin{abstract}
The effects of two kinds of meditation (open presence and focused) on the facial and physiological aspects of the defensive response to an aversive startle stimulus were studied in a Buddhist monk with approximately 40 years of meditation experience. The participant was exposed to a $115-\mathrm{db}, 100-\mathrm{ms}$ acoustic startle stimulus under the 2 meditation conditions, a distraction condition (to control for cognitive and attentional load) and an unanticipated condition (startle presented without warning or instruction). A completely counterbalanced 24-trial, single-subject design was used, with each condition repeated 6 times. Most aspects of the participant's responses in the unanticipated condition did not differ from those of a comparison group of 12 age-matched male controls. Both kinds of meditation produced physiological and facial responses to the startle that were smaller than in the distraction condition. Within meditation conditions, open presence meditation produced smaller physiological and facial responses than focused meditation. These results from a single highly expert meditator indicate that these 2 kinds of meditation can differentially alter the magnitude of a primitive defensive response.
\end{abstract}

Keywords: meditation, startle response, emotion, Buddhism

A flurry of studies of meditation appeared in the scientific literature in the 1970s, arguably stimulated by popular interest in Transcendental Meditation (a mantra-oriented meditation developed by the Maharishi Mahesh Yogi and popularized by many iconic figures of the day, including the Beatles). These earliest studies focused on the question of whether the physiological state associated with meditation was different than that of other relaxed states such as sleep or hypnosis (e.g., Benson, Beary, \& Carol, 1974; Wallace \& Benson, 1972). Evaluations of clinical applications of meditation soon followed (Gelderloos, Walton, OrmeJohnson, \& Alexander, 1991). In recent years there has been a revived interest in meditation in scientific circles, stimulated in part by the active dialog that western scientists have had with the Dalai Lama and his followers (e.g., Ekman, Davidson, Ricard, \& Wallace, 2005). In this new round of studies, the focus has expanded to include the impact of meditation and mind training on a broad range of psychological and physiological functions (Andresen, 2000; Davidson et al., 2003; Lutz, Slagter, Dunne, \& Davidson, 2008; Murphy \& Donovan, 1997; Sze, Gyurak, Yuan, \& Levenson, 2010; Walsh \& Shapiro, 2006).

This article was published Online First April 16, 2012.

Robert W. Levenson, Department of Psychology, University of California, Berkeley; Paul Ekman, Department of Psychiatry, University of California, San Francisco; Matthieu Ricard, Shechen Tennyi Dargyeling Monastery, Kathmandu, Nepal.

This research was supported by National Institute on Aging grants AG017766 and AG019724 (Robert W. Levenson).

Correspondence concerning this article should be addressed to Robert W. Levenson, Department of Psychology, 3210 Tolman Hall, University of California, Berkeley, CA 94720-1650. E-mail: boblev@ socates.berkeley.edu
Throughout the history of this research, many studies have considered the physiological concomitants of meditation. Typically, these studies have examined the acute effects of meditation on tonic, resting, or baseline physiological levels, usually in comparison with nonmeditative states. The pattern of findings from this work has not been very consistent. This may reflect the fact that studies have varied widely in terms of the particular type of meditation studied (each of which might produce different physiological states), the experience level of the meditators, and the conditions under which the physiological measures were obtained.

Other meditation research, more closely aligned with the individual differences tradition, has asked whether those who meditate regularly differ from those who do not. For example, a recent study using structural brain imaging (Hölzel et al., 2007) revealed that experienced practitioners of Vipassana meditators had greater gray matter concentrations in right anterior insula, left inferior temporal gyrus, and right hippocampus (brain regions that are thought to be activated during meditative states) compared with nonmeditating controls. A recent study from our laboratory found that experienced Vipassana meditators showed greater coherence between subjective emotional experience and physiological activity when in the throes of emotion than equally experienced dancers or nonmeditating, nondancing controls (Sze, Gyurak, Yuan, \& Levenson, 2010). These kinds of group differences are clearly intriguing; however, they beg the question of whether differences between meditators and controls predate or result from meditation training and practice.

\section{Meditation and the Startle Response}

The present study focuses on a somewhat different question. Rather than attempting to characterize the physiological state that 
occurs when one engages in a particular kind of meditation, we asked whether different meditative foci, when produced by a highly experienced practitioner, can modulate the physiological (somatic, facial expressive, autonomic) responses to a high amplitude $(115 \mathrm{db})$ aversive acoustic startle stimulus. The startle response to this kind of stimulus is best characterized as "defensive," a neurologically primitive, phylogenetically ancient reflexive response thought to protect the organism from injury (Koch, 1999). In rodents, the neural circuitry underlying the startle response has been well characterized, shown to be mediated by five neural synapses at the level of the brainstem plus the neuromuscular junction (Davis, Gendelman, Tischler, \& Gendelman, 1982). Consistent with this anatomy, the startle reflex can be observed in encephalic human newborns (Landis \& Hunt, 1939). The behavioral features of the startle response have been well characterized in humans, consisting of an initial fairly stereotyped, rapid set of muscle contractions in the upper torso (e.g., shoulder raising) and face (e.g., hard eye closure), followed by a more variable set of secondary emotional responses such as amusement, embarrassment, fear, and anger (Ekman, Friesen, \& Simons, 1985; Sturm, Rosen, Allison, Miller, \& Levenson, 2006). The startle response is also accompanied by large autonomic responses, which are thought to provide support for the associated somatic activity and help prepare the organism for action (Hagemann, Levenson, \& Gross, 2006; Roberts et al., 2004; Soto, Levenson, \& Ebling, 2005; Sturm et al., 2006).

The magnitude of the startle response to a high amplitude acoustic stimulus can be influenced by a number of psychological factors including knowledge of when the startle will occur (which is associated with reduction in the magnitude of response; Ekman et al., 1985; Hagemann et al., 2006; Keltner \& Ekman, 1996) and explicit instructions to control the response (Hagemann et al., 2006; Soto et al., 2005). Using a startle stimulus of considerably lower amplitude (approximately 95-105 db), a large body of research has shown that the amplitude of the eyeblink portion of the response can be modulated by attentional, cognitive, and emotional states. Attentional and cognitive demands have been shown to inhibit the startle response (Swerdlow, Caine, Braff, \& Geyer, 1992). The effects of emotional states are thought to be bidirectional, with positive emotional states attenuating and negative emotional states potentiating the magnitude of the startle eyeblink (Lang, Bradley, \& Cuthbert, 1990; Miller, Patrick, \& Levenston, 2002). It is likely that most modulatory effects are mediated by frontal brain regions, which are also involved in the secondary emotional responses to the defensive startle (Sturm et al., 2006) and with emotion regulation in general (Goodkind, Gyurak, McCarthy, Miller, \& Levenson, 2010; Gyurak et al., 2009; Ochsner et al., 2009). Taken together, these findings support the possibility that the defensive startle response could be modulated by different meditative states and underscore the importance of including controls for other nonmeditative influences.

\section{The Present Study}

Meditative techniques differ greatly in terms of the focus of attention, the way the meditative state is achieved, and the desired mental state. Most prior studies have compared a particular kind of meditation with a nonmeditative control state (for an exception comparing three meditative techniques, see Peng et al., 2004). In the present study, we compared two different, well-defined meditative techniques. We also included two additional conditions that enabled us to control for cognitive/attentional demands and to evaluate the response to the startle sans meditation.

Most prior studies of meditation have used between-groups designs with participants who have varying levels of meditative experience. To maximize the fidelity of the meditation manipulation, we used a different approach. We adopted a single case design using a highly skilled and experienced meditator who would be able to enter and maintain different meditative states on command and be comfortable with the repetitive methodology necessary for this experimental design. Ricard (one of the authors of this article) was ideal for this role, having been a Buddhist practitioner for over 40 years, and before that having completed a doctoral degree in the biological sciences. Ricard suggested that we contrast two kinds of meditation that are thought to represent the primary forms of meditation (Walsh \& Shapiro, 2006): (a) open presence, which aims for open focus and fluid attention, and (b) focused, which aims for continuous focus on a particular object in the environment. Stated in more perceptual terms, these two meditative states engender vastly different breadths of attentional focus, providing quite different backgrounds against which the startle stimulus would emerge. To these meditation conditions, we added two additional nonmeditation conditions: (c) distraction, in which the attentional focus was on a particular event that had occurred in the past, and (d) unanticipated, in which the startle stimulus was presented without warning or instructions.

\section{Method}

\section{Subject}

Ricard was born in 1946 and received his Ph.D. in biochemistry in 1972 at the Institute Pasteur working with Nobel laureate Francois Jacob. He became interested in Buddhist teachings during a visit to the Himalaya in 1967 and studied with renowned teachers Kangyur Rinpoche and Dilgo Khyentse Rinpoche. Ricard has lived in the Himalaya since 1979, completed several years of solitary retreat, and was ordained as a monk in 1979. He has lived in the Shechen Tennyi Dargyeling Monastery in Nepal since 1989. He has written a number of books on Buddhism (Revel \& Ricard, 1999; Ricard, 2006; Ricard \& Trinh, 2001) and serves as the Dalai Lama's French interpreter.

As a well-trained scientist, Ricard was interested in our research and often gave us extremely helpful suggestions about how best to implement our aims. As much as possible, we kept him blind as to our hypotheses, did not ask him to speculate ahead of time on the possible effects of meditation on the measured aspects of the startle response, and did not share our results with him until after the study had concluded. During the period we worked with him, he was also studied in several other laboratories (R. Davidson at Wisconsin; J. Cohen at Princeton, T. Singer in Maastricht and Zurich, S. Kosslyn at Harvard).

\section{Apparatus}

Facial behavior. Facial behavior was recorded continuously throughout the experiment using a partially hidden remotely con- 
trolled camera located behind darkened glass in a bookcase situated across from the participant.

Physiological. Autonomic and somatic nervous system responses were monitored continuously throughout the experiment using a system consisting of a Grass Model 7 polygraph and a microcomputer. Software written by one of the authors (Levenson) was used to compute second-by-second averages for a number of autonomic and somatic variables. Because this is a single case study with a small control group, we wanted to reduce the number of dependent measures. Thus, on an a priori basis we decided to focus on one cardiac (cardiac interbeat interval), one vascular (finger pulse amplitude), one electrodermal (skin conductance level), and one somatic measure (general somatic activity). These measures were obtained as follows: (a) heart rate (Beckman miniature electrodes with Redux paste were placed in a bipolar configuration on opposite sides of the participant's chest; the interbeat interval was calculated as the interval, in milliseconds, between successive R waves), (b) finger pulse amplitude (an UFI photoplethysmograph recorded the amplitude of blood volume in the finger using a photocell taped to the distal phalange of the index finger of the nondominant hand), (c) skin conductance level (a constant-voltage device was used to pass a small voltage between Beckman regular electrodes [using an electrolyte of sodium chloride in unibase] attached to the palmar surface of the middle phalanges of the ring and index fingers of the nondominant hand), and (d) general somatic activity (an electromechanical transducer attached to the platform under the participant's chair generated an electrical signal proportional to the amount of movement in any direction).

These four measures provide a reasonably broad sampling of the activity of autonomic and somatic systems important to startle responding. In addition, they were used in our prior studies of the startle response (Goodkind et al., 2010; Gyurak et al., 2009; Hagemann et al., 2006; Roberts et al., 2004; Soto et al., 2005; Sturm et al., 2006), thus providing comparability across studies. Importantly, including the additional physiological measures we obtained but did not include in this article (i.e., pulse transmission times to the finger and ear, systolic and diastolic blood pressure, respiratory rate and depth) would not change the reported results in any significant way.

\section{Procedure}

Ricard came to the Berkeley Psychophysiology Laboratory at the University of California, Berkeley on three separate occasions over the course of three years. Initially we studied a number of different aspects of his emotional responding, assessing subjective, expressive, and physiological responses when viewing emotionally arousing films, engaging in conversations with agreeable and disagreeable partners, and reliving emotional memories. As the work progressed, we began to focus on the startle response as a way to study the impact of different types of meditation systematically. For this purpose, the startle response has the virtue of being appropriate for repeated administrations (vs. films, where familiarity can alter the response, Gross \& Levenson, 1995), highly controllable (vs. conversations, which are much more variable), and not requiring the participant to self-generate the emotional stimulus (vs. relived emotional memories, which vary de- pending on the person's emotional history and ability to access memories).

The startle was administered using procedures we have used previously (e.g., Hagemann et al., 2006; Soto et al., 2005; Sturm et al., 2006). The startle stimulus was a 115-db, 100-ms burst of white noise presented through hidden loudspeakers located behind the subject's head. This produces a gunshot-like sound (Ekman et al., 1985, used an actual gunshot), which is sufficiently loud to produce a strong defensive reaction. In a previous study, we found that the test-retest reliability of the unanticipated startle over a 1-year period was .71 (Gyurak et al., 2009).

Each experimental trial consisted of a 60 -s prestartle period, a 20-s countdown in which numbers from 10 to 1 signaled the impending startle (the countdown was not present in the unanticipated startle condition), the startle stimulus, and a 90-s poststartle period. There were four kinds of trials.

(a) Open presence meditation (also known as "pure awareness"). The participant was instructed to enter a meditative state of openness that was "very vast, clear, vivid and lucid and fully resting in the moment." The trial began once he indicated he had achieved this state.

(b) Focused meditation (also known as "fixed point"). The participant was instructed to enter a meditative state focusing on a detail in the experimental environment: "your mind is gathered into a point, whether it is the present moment or an object, you try to keep your attention on something." Ricard reported that his mind was totally focused on the countdown. The trial began once he indicated he had achieved this state.

(c) Distraction. The participant was instructed to think in detail about a particular incident from the past (i.e., a meeting or place). The trial began once he indicated he had achieved this state. In consultation with Ricard, the distraction trial was included to provide a nonmeditative condition that involved cognitive and attentional load that was comparable with that of the focused and open presence meditation conditions.

(d) Unanticipated startle. No instructions or countdown were presented and the participant was unaware that the trial had started. There were no meditative or other instructions in this condition. This provided an assessment of Ricard's "basic" startle response that could be compared with those of other men his age that we had studied previously.

To control for order effects and for habituation to the startle stimulus, and to increase the opportunities for within-subject replication, a completely counterbalanced design was used. The set of four experimental conditions was repeated six times, each with a different ordering of the conditions (the sequencing of the six orders was chosen at random). Thus, there were a total of 24 trials. Each trial lasted for approximately $3 \mathrm{~min}$ and was followed by questions as to any thoughts, emotions, or sensations that had occurred. All trials were conducted in a single 120-min experimental session.

\section{Results}

\section{Data Reduction}

Facial behavior. Facial behavior was scored using the facial action coding system (FACS) (Ekman \& Friesen, 1978) by one of the authors (Ekman), who was blind as to experimental condition. 
Because the intensity of the Ricard's startle response was so low, we expanded the normal 5-point FACS intensity scale to a 7-point scale. On this expanded scale, an intensity score of "2" is equal to a score of " 1 " on the normal scale. The mean intensity for each startle response was determined by averaging the intensity scores for all action units that occurred during the initial facial response to the startle stimulus. We also examined the ensuing $5 \mathrm{~s}$ for any secondary emotional responses that occurred in response to being startled. A subsample of the initial startle responses was scored by a second trained coder, also blind as to condition, to assure that the scoring was reliable. The agreement coefficient was .78, which is consistent with other research using FACS (Ekman \& Rosenberg, 2005).

Physiological. For each physiological measure, on each of the 24 trials, the $60 \mathrm{~s}$ prior to the startle were averaged as well as the 5-s period beginning with the startle. A reactivity score was then computed (startle period average minus prestartle period average). These reactivity scores control for changes in prestartle levels that typically occur over the course of a multitrial experiment.

\section{Response to Unanticipated Startle: Ricard Versus Controls}

The unanticipated startle trial provided an opportunity to compare Ricard's response in a nonmeditative, nonwarned, noninstructed state with those of comparably well-educated men his age who do not have his extensive meditation experience. For this comparison, we utilized data from the unanticipated startle condition (administered using the same procedures in the same setting used with Ricard) obtained from 12 neurologically normal male control subjects who had participated in our research on emotional functioning in neurological patients (e.g., Sturm et al., 2006). The control subjects were 67 years old on average and well-educated; thus, they provided a reasonable comparison group.

Physiological. Physiological responses for Ricard and controls for the four physiological measures are depicted in Figure 1. Examination of Ricard's responses in relationship to the mean responses of the controls reveals that Ricard's responses were well within the $95 \%$ confidence intervals for cardiac interbeat interval, general somatic activity, and finger pulse amplitude. Ricard's skin conductance level response was slightly higher than the control group's confidence interval. Moreover, there was no obvious pattern in the mean differences. For two of the variables (cardiac interbeat interval and skin conductance), Ricard's responses were numerically larger than the controls, and for the other two variables (general somatic activity and finger pulse amplitude) they were smaller. Thus, we conclude that the physiological aspects of Ricard's startle response were quite similar in magnitude to that of the comparison group.

Facial behavior. We were not able to compare Ricard's facial responses with the unanticipated startle with those of the controls because the latter had not been coded with FACS. However, based on our past experience with this task with men his age, Ricard's facial response to the first administration of the unanticipated startle was quite consistent in terms of morphology (i.e., the facial response included FACS action units 1, 2, 20, 43, 53, and 73) but much smaller in terms of intensity (i.e., less than 1 using the standard FACS 1-5 intensity scale). Although we have not previously exposed participants to the large numbers of startles that we exposed Ricard to, we might expect to see some evidence of habituation (or sensitization) over repetitions. Examining the intensity of Ricard's facial responses across the six repetitions of the unanticipated startle revealed essentially no change (slope of
Cardiac Interbeat Interval

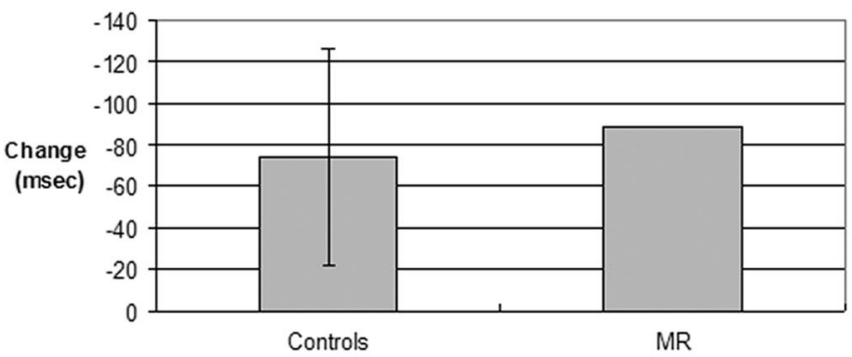

Skin Conductance Level

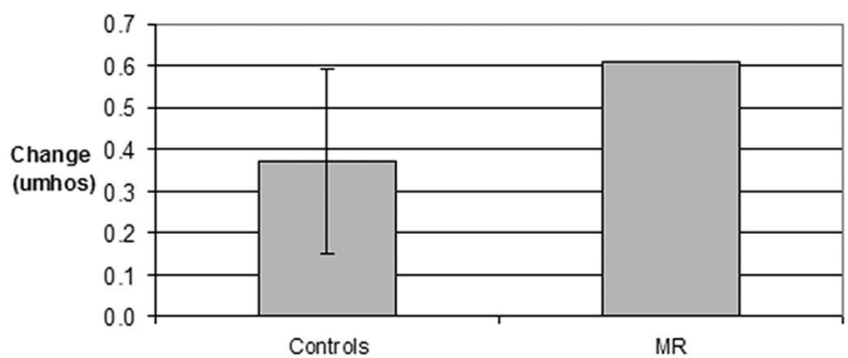

General Somatic Activity

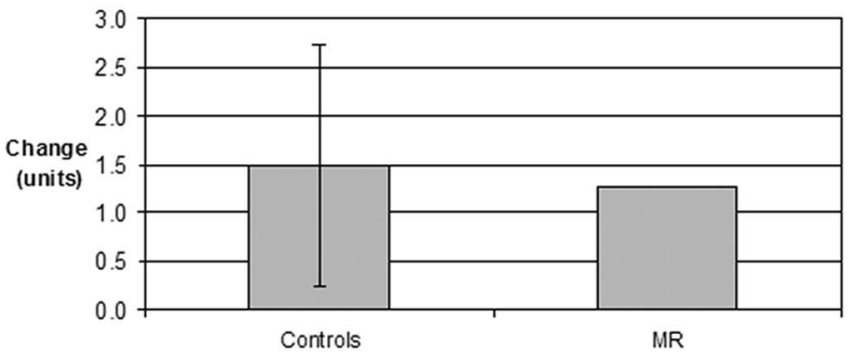

Finger Pulse Amplitude

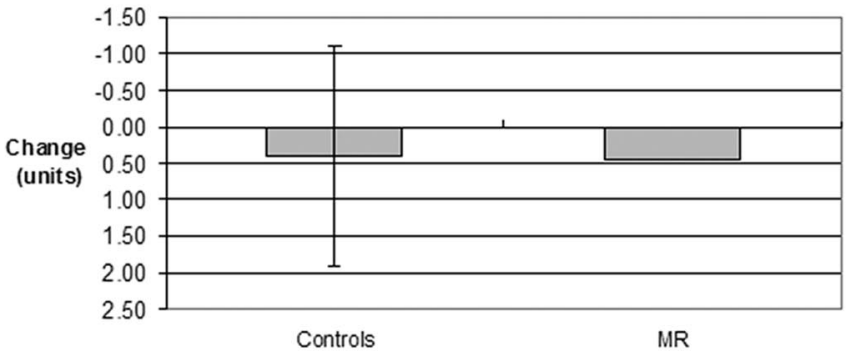

Figure 1. Physiological response to unanticipated startle in controls (with 95\% confidence intervals) and Ricard. All responses are scaled so that greater activation is in the upwards direction. 
linear regression line $=.007$; mean intensities of facial actions: 1.50, 2.00, 1.00, 2.50, 1.00, 1.75).

Interestingly, Ricard never showed any of the "secondary" emotional responses (e.g., amusement, embarrassment, fear, anger) to being startled that we have observed following the initial startle response in older (Sturm et al., 2006) and younger adults (Ekman et al., 1985). To put this in perspective, embarrassment is one of the common secondary emotional responses to startle. In the study that provided the comparison group used in the present study, $35 \%$ of the neurologically normal participants showed facial signs of embarrassment (Sturm et al., 2006).

\section{Impact of Meditation on the Startle Response}

Meditation versus distraction. As can be seen in Figure 2, the startle response during the open presence meditation condition appeared to be appreciably smaller than during the distraction condition for all physiological variables and for facial behavior. The response during the focused meditation condition also ap-

\section{Cardiac Interbeat Interval}

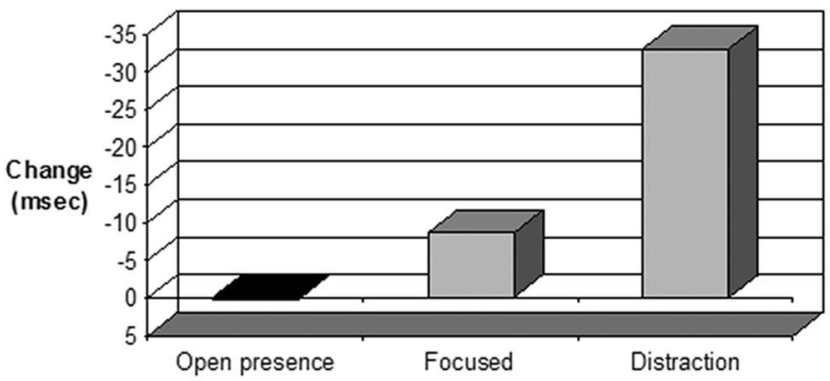

Skin Conductance

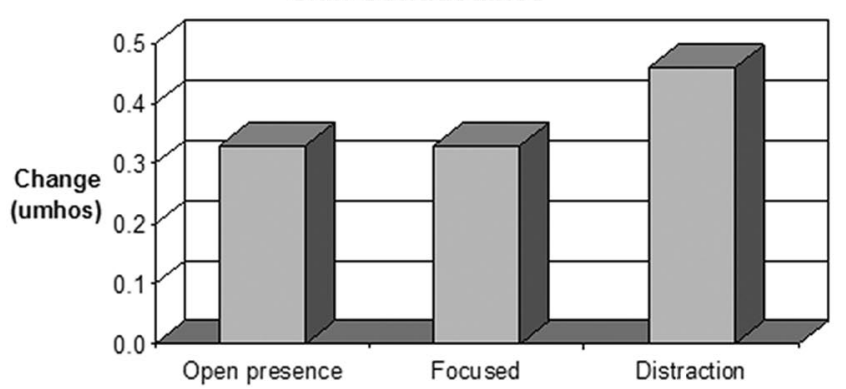

peared to be smaller than during the distraction condition for cardiac interbeat interval, general somatic activity, skin conductance, and facial behavior, but not for finger pulse amplitude.

With only one subject, parametric statistics are not possible. However, we were able to apply a nonparametric test of proportions to test the consistency of observed patterns (i.e., responses are smaller on the meditation trials than on the distraction trial). To make this test more conservative, if the two responses were equal, then the pattern was counted as not present. For general somatic activity and skin conductance level, larger values (i.e., more muscle and sweat gland activity) were counted as larger responses. For cardiac interbeat interval and finger pulse amplitude, smaller values (i.e., faster heart rate and greater vasoconstriction) were counted as larger responses. For facial behavior, greater average intensity of facial actions was counted as a larger response.

For the 24 possible physiological comparisons, the pattern of physiological responses being smaller during open presence meditation than during the distraction condition was found 18 times. A
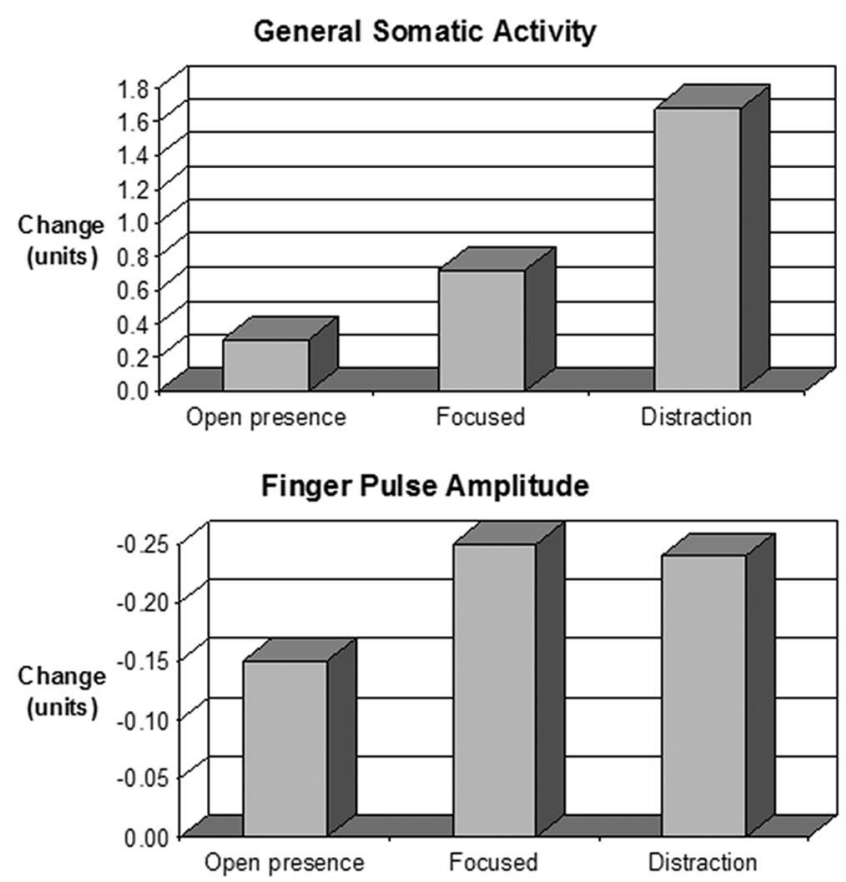

Facial behavior

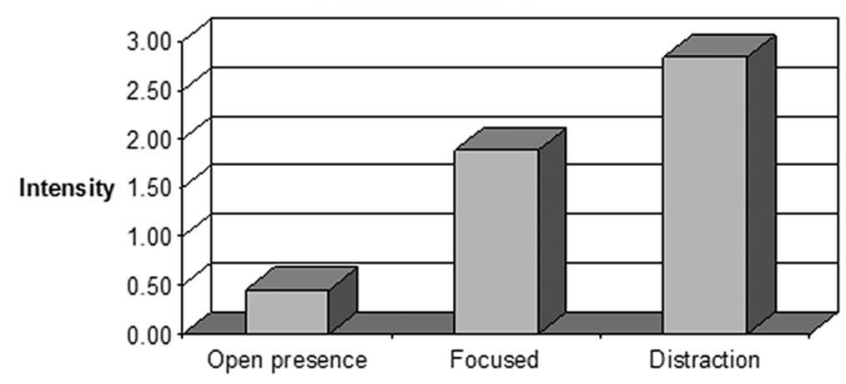

Figure 2. Average physiological and facial behavioral response to unanticipated startle across six replications of open presence meditation, focused meditation, and distraction conditions in Ricard. All responses are scaled so that greater activation is in the upwards direction. 
nonparametric test of the 18 "hits" out of 24 total comparisons (assuming a chance rate of 50\%) was significant, $z=2.45, p<$ .05. Similarly, the pattern of physiological responses being smaller during focused meditation than during the distraction condition was found 18 times. A nonparametric test of the 18 "hits" out of 24 total comparisons (assuming a chance rate of 50\%) was significant, $z=2.45, p<.05$.

For the six possible facial behavior comparisons, the pattern of facial behavioral responses being less intense during open presence meditation than during the distraction condition was found six times. A nonparametric test of the six "hits" out of six total comparisons (assuming a chance rate of 50\%) was significant, $p<$ .05. Similarly, the pattern of facial behavioral responses being less intense during focused meditation than during the distraction condition was also found six times. A nonparametric test of the six "hits" out of six total comparisons (assuming a chance rate of $50 \%$ ) was significant, $p<.05$.

Thus, we conclude that the physiological and facial behavioral aspects of the startle response were consistently smaller during the two kinds of meditation that during the distraction condition.

Open presence versus focused meditation. We next turned to the question of whether there were differences between the two kinds of meditation. The averaged autonomic, somatic, and facial responses to the startle during open presence and focused meditation can be seen in Figure 2. Visual examination of this figure reveals that the cardiovascular (cardiac interbeat interval and finger pulse amplitude), somatic (general somatic activity), and facial behavioral responses to the startle appear to be appreciably smaller on the open presence meditation trials than on the focused meditation trials. For the electrodermal measure (skin conductance), the responses appear to be equivalent.

To evaluate the stability of these patterns, we conducted a test of the consistency of the pattern of smaller responses during open presence meditation compared with focused meditation as described above. For each of the six times that the open presence and focused meditations were attempted, for each of the four physiological and one facial measures, we determined whether this pattern was present or not. As before, to make the analysis more conservative, if the responses were equal in the two conditions, the pattern was counted as not present.

For the physiological measures, results indicated that for the 24 possible comparisons (4 measures $\times 6$ counterbalanced replications), the pattern of smaller responses during open presence meditation than during focused meditation was found 17 times. A nonparametric test of the 17 "hits" out of 24 total comparisons (assuming a chance rate of 50\%) was significant, $z=2.04, p<.05$.

For the facial measure, results indicated that for the six possible comparisons (six counterbalanced replications), the pattern of smaller responses during open presence meditation than during focused meditation was found six times. A nonparametric test of the six "hits" out of six total comparisons (assuming a chance rate of $50 \%$ ) was significant, $p<.05$.

Thus, we conclude that the pattern of physiological and facial behavioral responses to the startle being smaller during open presence meditation than during focused meditation was reliable.

\section{Discussion}

In this study, we examined the capacity of two different kinds of meditation to modulate the autonomic, somatic, and facial aspects of the defensive startle response to an aversive auditory stimulus. A single subject, Matthieu Ricard, a Buddhist monk with four decades of meditation experience was studied. A single case experimental design was utilized in which Ricard was exposed to the startle stimulus under four different experimental conditions, each repeated six times in fully counterbalanced order. This study had a number of novel features including: (a) using a participant who was a Buddhist monk and a highly experienced meditator; (b) comparing two different kinds of meditation; (c) including a control condition that enabled comparison of meditation with a nonmeditative state that made cognitive and attentional demands comparable with those associated with meditation; (d) including a condition in which the startle appeared without warning or instructions, which enabled comparison of Ricard's basic startle response with that of a group of men of similar age and education; and (e) focusing on the capacity of meditation to modulate a primitive, reflexive response rather than assessing its acute effects on resting physiology (as has been the case in much of the previous literature).

\section{Ricard's Startle Response Comparable With Controls}

Comparing Ricard's physiological response to the unanticipated startle (presented without instructions or warning) with that of a group of men of comparable age and education but without his extensive meditation experience indicated that the autonomic and gross motor aspects of his startle response fell within normal bounds. Given that the startle response is mediated by low-level brainstem circuitry (Davis et al., 1982), it is not surprising to find that these aspects of his response were not affected in any significant way by his being an experienced meditator. Ricard's life experiences have surely been profoundly transformative in many ways; however, they do not seem to have penetrated to these primitive reaches of his nervous system.

Ricard's facial response to the unanticipated startle was also similar to those we have seen previously in terms of the pattern of facial muscles activated. However, it was much smaller in intensity. We do not know why only this particular aspect of the facial behavioral response to startle differed from the norm. It may be idiosyncratic, existing prior to his meditative experience, or it may result from certain aspects of his Buddhist training and practice. Studies of the facial behavioral response to startle in individuals before and after undergoing meditation training could help illuminate this matter.

\section{Reduction of the Startle Response by Meditation}

Compared with the distraction condition (a nonmeditative condition designed to make comparable cognitive and attentional demands), both open presence and focused meditation resulted in significantly reduced physiological and facial responses. We consider this to be an impressive demonstration of the power of meditation to exert top-down influence on the startle response. As reviewed earlier, there is a large literature indicating that the eyeblink response to an acoustic startle stimulus can be modulated 
by emotion and by attentional and cognitive load. However, this work has used lower amplitude, much less aversive, and, hence, presumably easier to control stimuli. In the startle eyeblink literature, the stimulus is often referred to as a background probe; in the present study, the stimulus was prominently in the foreground. All of these factors combine to make it even more impressive that meditation was able to reduce the defensive startle response. Moreover, the distraction control condition suggests that this reduction goes beyond that which is produced by the cognitive act of voluntarily reallocating attention.

Also noteworthy is the finding that meditation reduced the autonomic cardiovascular response to startle. In our prior work, when we explicitly instructed subjects to inhibit their behavioral response to this same high-amplitude aversive startle stimulus, the result was a larger autonomic response (Hagemann et al., 2006). The fact that meditation caused a decrease in the autonomic response suggests that Ricard was not simply trying to inhibit his somatic response. As he made clear in his description of the two meditations, he was controlling his attentional focus and not his muscles.

\section{Open Presence Versus Focused Meditation}

There was clear indication that open presence meditation produced an even smaller startle response than did focused meditation. This was evidenced in the measure of somatic activity, the two cardiovascular measures, and in the intensity of facial response (but not in the electrodermal measure). Because the cardiac response is intimately tied to the demands created by the somatic musculature (Obrist, 1981), it is quite possible that the primary effect of open meditation was to reduce Ricard's somatic response to the aversive stimulus and that his nervous system then reduced the cardiovascular response accordingly. The fact that the electrodermal response did not follow suit is consistent with this view. Electrodermal responding is not as closely linked to somatic demand as is cardiovascular responding for both functional reasons (i.e., muscle actions are highly dependent on oxygenated blood, but not on sweat) and anatomical reasons (i.e., the sweat glands do not have the same postsynaptic adrenergic neurochemistry found in most organs innervated by the sympathetic nervous system). Thus, these findings suggest that open meditation was not acting "across-the-board" to reduce all aspects of autonomic responding.

The finding that open presence meditation had greater potency to reduce the physiological and facial response to the startle than focused meditation, and the greater potency of both forms of meditation to reduce the startle response as compared with the distraction condition can also be understood in terms of the nature of the three states as described by Ricard.

In the open presence meditation condition, fully in the present moment, Ricard reported experiencing the noise associated with the startle stimulus to be no more than one of those present moments. Engaged in open presence meditation, he did not have to be brought back to the present moment because he was already there. There was no need to disengage from a particular content, and, thus, his reaction was reduced. In the focused meditation condition, in contrast, his mind was fixed on an incoming event that keep the mind directed, but he was not resting in the present moment without any expectation. When the loud noise occurred there was a small shift in attention, thus, subjectively it was intermediate between distraction and open presence. In the distraction condition, he was deeply engaged in recollecting past events, his mind was completely distracted from the present moment, lost in thoughts and "internal chatter." When the startle occurred he was suddenly brought back to the reality of the present moment and that shift was reflected in the startle. He felt that the more the mind was wandering somewhere else, the stronger the startle response would be.

\section{Observations From Other Tasks}

During our three years of working with Ricard, we tried a number of other tasks, none of which were pursued as systematically as was the case with the defensive startle as reported here. Although these other tasks lacked the experimental rigor necessary for scientific publication, we still feel they may be of interest to others and may help place the startle findings in their larger context. Thus, we will briefly review this other work here with the hope that it will provide interesting leads that we and others might pursue more systematically in future work.

We showed Ricard a number of emotionally arousing films, of the sort we typically use in our emotion research (Gross \& Levenson, 1995). Our general experience is that, when allowed to give a free response describing their subjective experience, almost all subjects respond quite briefly. Ricard's descriptions, in contrast, were much more elaborated, rich in detail, and recounting the moment-to-moment changes that occurred in his emotional state. When asked to engage in a relived emotions task (Ekman, Levenson, \& Friesen, 1983) and asked to relive a time in his life when he had been angry, he had to go back 26 years to find an occasion when he had expressed anger. Most participants we have studied need only go back a few days or weeks at most.

Across tasks, we were repeatedly struck with how sensitive and attuned Ricard appeared to be to the physiological sensations that occurred during his emotional states. In a task in which we had him report the valence of his emotional state continuously using our rating dial methodology (Ruef \& Levenson, 2007), we were struck by how closely the changes in his ratings tracked the perturbations that occurred in a beat-by-beat measure of his blood pressure. Several years later, this observation led us to conduct a formal study of how closely subjective emotional experience tracks physiological changes during emotion in a sample of experienced Vipassana meditators, finding that this tracking is much closer than in those with a different kind of body-awareness training (experienced dancers) and in controls (Sze et al., 2010).

One of the most amusing and touching moments came when we used a modified version of the dyadic interaction task we use in our studies of how couples in intimate relationships deal with conflict (Levenson \& Gottman, 1983). In two different trials, Ricard was asked to discuss his belief in reincarnation with two scientists, chosen because of differences in their manner, but both of whom disagreed with his strongly held conviction. In his discussion with the scientist chosen because of his gentle manner, there was frequent mutual smiling, and neither showed a great deal of autonomic nervous system arousal. In his discussion with the scientist chosen because of his aggressive manner, there were few mutual smiles initially, and a high level of autonomic arousal was shown by the scientist, but not by Ricard. By the end of the allotted 15 min, more mutual smiling emerged, and the scientist's level of 
autonomic arousal had dropped markedly. This famously aggressive scientist volunteered after the session that there was something about Ricard that made it very difficult to fight with him.

\section{Strengths, Limitations, and Future Directions}

This study has several strengths and weaknesses. Studying a person with Ricard's extensive training and experience maximized the likelihood that the meditative states of interest were produced with the highest possible fidelity. This was critical for an initial determination of whether these states differentially modulate the startle response. Of course, as with any single case study, we cannot know the extent to which the findings will generalize to other meditators, including those with less extensive training and experience. Moreover, we do not know whether the differences we found between meditation and our distraction control condition and between the two forms of meditation using the startle response would be similar when applied to more complex emotion-eliciting situations (e.g., films, memories, social interactions). Finally, research reviewed in the introduction to this article has shown that the magnitude of the startle response can be reduced by warning, by cognitive and attentional load, and by underlying positive emotional states. By including the countdown condition in the two meditative conditions and the distraction condition, we were able to control for the effect of warning. Our distraction condition was an attempt to control for cognitive and attentional load, but of course we cannot know for certain that it was successful. Thus, it is quite possible that some of the reduction in startle magnitude associated with the two meditation conditions compared with the distraction condition resulted simply from greater cognitive and attentional demands involved in meditation. Finally, our conditions were not designed to differ in positive emotionality (and Ricard's descriptions and facial behavior did not seem to suggest that this was a primary difference). However, it is certainly conceivable that some of the gradient of reduced startle response moving from distraction to focused meditation to open presence meditation could be explained in terms of increasing positive emotionality (especially if the domain of positive emotion is expanded to include states such as contentment and awe; Fredrickson \& Levenson, 1998; Shiota, Keltner, \& Mossman, 2007).

One of the interesting questions that arose in this work with Ricard concerned the long-term effects of extensive meditative practice. In this regard, we found that Ricard's startle response in the unanticipated condition was quite comparable with that of others without his training and experience in terms of the magnitude of the physiological response and the morphology of the facial response. The only hint of difference was the finding that the amplitude of Ricard's facial response was smaller. Of course, as in most studies of this nature (including those that examine higherlevel, more complex emotional responses in experienced meditators and controls), we cannot know whether these differences result from meditation training, characteristics of this particular person, or some combination of both.

What this study indicates most clearly is that the act of engaging in meditation can modulate a reflexive response that is located in quite primitive regions of the human nervous system. This highlights an important question when considering the utility of meditation for influencing more complex responses such as our emotional reactions to life's challenges, opportunities, and stresses.
Meditation is believed by its practitioners to create a buffer against being overwhelmed by emotional states that would otherwise distort reality and result in actions or words that are harmful to the self and others. Viewed in this way, meditation can be an important adjunct to successful emotion regulation. Evaluating the outcomes of meditation training (with both normal individuals and those with psychiatric conditions) has been the subject of several recent studies (e.g., Fredrickson, Cohn, Coffey, Pek, \& Finkel, 2008; Goldin, Ramel, \& Gross, 2009; Johnson et al., 2009). For our understanding of the acute and long-term effects of meditation to flourish, additional basic and applied studies, all conducted with the highest levels of scientific rigor, will be needed.

We believe that the results of the present study, which derive from a systematic single case study of a highly experienced practitioner, illustrate the promise of this approach for increasing our understanding of what meditation is and what is does. We hope that the formal findings we presented and our more informal descriptions of the emotional characteristics we observed in our participant will be helpful to others who conduct basic research on meditation and who test the efficacy of its applications.

\section{References}

Andresen, J. (2000). Meditation meets behavioural medicine: The story of experimental research on meditation. Journal of Consciousness Studies, 7, 17-73.

Benson, H., Beary, J. F., \& Carol, M. P. (1974). The relaxation response. Psychiatry, 37, 37-46.

Davidson, R. J., Kabat-Zinn, J., Schumacher, J., Rosenkranz, M., Muller, D., Santorelli, S. F., . . . Sheridan, J. F. (2003). Alterations in brain and immune function produced by mindfulness meditation. Psychosomatic Medicine, 65, 564-570. doi:10.1097/01.PSY.0000077505.67574.E3

Davis, M., Gendelman, D. S., Tischler, M. D., \& Gendelman, P. M. (1982). A primary acoustic startle circuit: Lesion and stimulation studies. Journal of Neuroscience, 2, 791-805.

Ekman, P., Davidson, R. J., Ricard, M., \& Wallace, B. A. (2005). Buddhist and psychological perspectives on emotions and well-being. Current Directions in Psychological Science, 14, 59-63. doi:10.1111/j.09637214.2005.00335.x

Ekman, P., \& Friesen, W. V. (1978). Facial action coding system. Palo Alto, CA: Consulting Psychologists Press.

Ekman, P., Friesen, W. V., \& Simons, R. C. (1985). Is the startle reaction an emotion? Journal of Personality and Social Psychology, 49, 14161426. doi:10.1037/0022-3514.49.5.1416

Ekman, P., Levenson, R. W., \& Friesen, W. V. (1983). Autonomic nervous system activity distinguishes among emotions. Science, 221, 1208 1210. doi: $10.1126 /$ science. 6612338

Ekman, P., \& Rosenberg, E. L. (2005). What the face reveals: Basic and applied studies of spontaneous expression using the facial action coding system (FACS). In R. J. Davidson, P. Ekman, \& K. Scherer (Eds.), Series in affective science (2nd ed., Vol. xxi, p. 639). New York, NY: Oxford University Press.

Fredrickson, B. L., Cohn, M. A., Coffey, K. A., Pek, J., \& Finkel, S. M. (2008). Open hearts build lives: Positive emotions, induced through loving-kindness meditation, build consequential personal resources. Journal of Personality and Social Psychology, 95, 1045-1062. doi: $10.1037 / \mathrm{a} 0013262$

Fredrickson, B. L., \& Levenson, R. W. (1998). Positive emotions speed recovery from the cardiovascular sequelae of negative emotions. Cognition and Emotion, 12, 191-220. doi:10.1080/026999398379718

Gelderloos, P., Walton, K. G., Orme-Johnson, D. W., \& Alexander, C. N. (1991). Effectiveness of the transcendental meditation program in pre- 
venting and treating substance misuse: A review. International Journal of the Addictions, 26, 293-325.

Goldin, P., Ramel, W., \& Gross, J. (2009). Mindfulness meditation training and self-referential processing in social anxiety disorder: Behavioral and neural effects. Journal of Cognitive Psychotherapy. Special Issue: New developments in research on mindfulness-based treatments, 23, 242257.

Goodkind, M. S., Gyurak, A., McCarthy, M., Miller, B. L., \& Levenson, R. W. (2010). Emotion regulation deficits in frontotemporal lobar degeneration and Alzheimer's disease. Psychology and Aging, 25, 30-37. doi: $10.1037 / \mathrm{a} 0018519$

Gross, J. J., \& Levenson, R. W. (1995). Emotion elicitation using films. Cognition and Emotion, 9, 87-108. doi:10.1080/02699939508408966

Gyurak, A., Goodkind, M. S., Madan, A., Kramer, J. H., Miller, B. L., \& Levenson, R. W. (2009). Do tests of executive functioning predict ability to downregulate emotions spontaneously and when instructed to suppress? Cognitive Affective \& Behavioral Neuroscience, 9, 144-152. doi:10.3758/CABN.9.2.144

Hagemann, T., Levenson, R. W., \& Gross, J. J. (2006). Expressive suppression during an acoustic startle. Psychophysiology, 43, 104-112. doi:10.1111/j.1469-8986.2006.00382.x

Hölzel, B. K., Ott, U., Gard, T., Hempel, H., Weygandt, M., Morgen, K., \& Vaitl, D. (2007). Investigation of mindfulness meditation practitioners with voxel-based morphometry. Social Cognitive and Affective Neuroscience, 3, 55-61. doi:10.1093/scan/nsm038

Johnson, D. P., Penn, D. L., Fredrickson, B. L., Meyer, P. S., Kring, A. M., $\&$ Brantley, M. (2009). Loving-kindness meditation to enhance recovery from negative symptoms of schizophrenia. Journal of Clinical Psychology, 65, 499-509. doi:10.1002/jclp.20591

Keltner, D., \& Ekman, P. (1996). Affective intensity and emotional responses. Cognition and Emotion, 10, 323-328. doi:10.1080/ 026999396380277

Koch, M. (1999). The neurobiology of startle. Progress in Neurobiology, 59, 107-128. doi:10.1016/S0301-0082(98)00098-7

Landis, C., \& Hunt, W. A. (1939). The startle pattern. New York, NY: Farrar \& Rinehart.

Lang, P. J., Bradley, M. M., \& Cuthbert, B. N. (1990). Emotion, attention, and the startle reflex. Psychological Review, 97, 377-395. doi:10.1037/ 0033-295X.97.3.377

Levenson, R. W., \& Gottman, J. M. (1983). Marital interaction: Physiological linkage and affective exchange. Journal of Personality and Social Psychology, 45, 587-597. doi:10.1037/0022-3514.45.3.587

Lutz, A., Slagter, H. A., Dunne, J. D., \& Davidson, R. J. (2008). Attention regulation and monitoring in meditation. Trends in Cognitive Science, 12, 163-169. doi:10.1016/j.tics.2008.01.005

Miller, M. W., Patrick, C. J., \& Levenston, G. K. (2002). Affective imagery and the startle response: Probing mechanisms of modulation during pleasant scenes, personal experiences and discrete negative emotions. Psychophysiology, 39, 519-529. doi:10.1017/S0048577202394095

Murphy, M., \& Donovan, S. (1997). The physical and psychological effects of meditation. Petaluma, CA: Institute of Noetic Sciences.

Obrist, P. A. (1981). Cardiovascular psychophysiology. New York, NY: Plenum Press.
Ochsner, K. N., Ray, R. R., Hughes, B., McRae, K., Cooper, J. C., Weber, J., . . Gross, J. J. (2009). Bottom-up and top-down processes in emotion generation: Common and distinct neural mechanisms. Psychological Science, 20, 1322-1331. doi:10.1111/j.1467-9280.2009.02459.x

Peng, C. K., Henry, I. C., Mietus, J. E., Hausdorff, J. M., Khalsa, G., Benson, H., \& Goldberger, A. L. (2004). Heart rate dynamics during three forms of meditation. International Journal of Cardiology, 95, 19-27. doi:10.1016/j.ijcard.2003.02.006

Revel, J. F., \& Ricard, M. (1999). The monk and the philosopher: A father and son discuss the meaning of life. New York, NY: Schocken Books.

Ricard, M. (2006). Happiness: A guide to developing life's most important skill. New York, NY: Little Brown.

Ricard, M., \& Trinh, X. T. (2001). The quantum and the lotus: A journey to the frontiers where science and Buddhism meet. New York, NY: Crown Publishers.

Roberts, N. A., Beer, J. S., Werner, K. H., Scabini, D., Levens, S. M., Knight, R. T., \& Levenson, R. W. (2004). The impact of orbital prefrontal cortex damage on emotional activation to unanticipated and anticipated acoustic startle stimuli. Cognitive, Affective, \& Behavioral Neuroscience, 4, 307-316. doi:10.3758/CABN.4.3.307

Ruef, A. M., \& Levenson, R. W. (2007). Continuous measurement of emotion. In J. A. Coan \& J. J. B. Allen (Eds.), The handbook of emotion elicitation and assessment (pp. 286-297). New York, NY: Oxford University Press.

Shiota, M. N., Keltner, D., \& Mossman, A. (2007). The nature of awe: Elicitors, appraisals, and effects on self-concept. Cognition and Emotion, 21, 944-963. doi:10.1080/02699930600923668

Soto, J. A., Levenson, R. W., \& Ebling, R. (2005). Cultures of moderation and expression: Emotional experience, behavior, and physiology in Chinese Americans and Mexican Americans. Emotion, 5, 154-165. doi:10.1037/1528-3542.5.2.154

Sturm, V. E., Rosen, H. J., Allison, S., Miller, B. L., \& Levenson, R. W (2006). Self-conscious emotion deficits in frontotemporal lobar degeneration. Brain: A Journal of Neurology, 129, 2508-2516. doi:10.1093/ brain/awl145

Swerdlow, N. R., Caine, S. B., Braff, D. L., \& Geyer, M. A. (1992). The neural substrates of sensorimotor gating of the startle reflex: A review of recent findings and their implications. Journal of Psychopharmacology, 6, 176-190. doi:10.1177/026988119200600210

Sze, J. A., Gyurak, A., Yuan, J. W., \& Levenson, R. W. (2010). Coherence between emotional experience and physiology: Does body awareness training have an impact? Emotion, 10, 803-814. doi:10.1037/a0020146

Wallace, R. K., \& Benson, H. (1972). The physiology of meditation. Scientific American, 226, 84-90. doi:10.1038/scientificamerican0272-84

Walsh, R., \& Shapiro, S. L. (2006). The meeting of meditative disciplines and western psychology: A mutually enriching dialogue. American Psychologist, 61, 227-239. doi:10.1037/0003-066X.61.3.227

Received August 28, 2008

Revision received August 1, 2011 Accepted October 11, 2011 